\title{
Identification of lactic acid bacteria in traditional fermented yak milk and evaluation of their application in fermented milk products
}

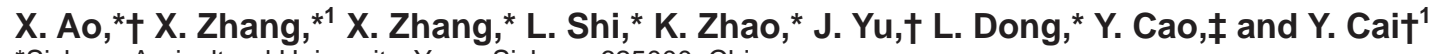 \\ *Sichuan Agricultural University, Yaan, Sichuan 625000, China \\ †Japan International Research Center for Agricultural Sciences (JIRCAS), 1-1 Ohwashi, Tsukuba, Ibaraki 305-8686, Japan \\ ¥Northeast Institute of Geography and Agroecology, Chinese Academy of Sciences, Changchun 130012, China
}

\section{ABSTRACT}

In this study, 53 strains of lactic acid bacteria (LAB) isolated from Xueo, a traditional fermented yak milk in the western Sichuan Plateau of China, were identified and their use in fermented milk was evaluated. All grampositive and catalase-negative strains were divided into 6 groups at the level of $87 \%$ similarity using amplified ribosomal DNA restriction analysis. These groups were identified as 6 species using $16 \mathrm{~S}$ rDNA sequence analysis and atpA gene analysis. The dominant LAB strains in Xueo were Enterococcus durans, Lactobacillus fermentum, and Lactobacillus paracasei, accounting for $45.3,22.6$, and $17.0 \%$ of isolates, respectively. Milk fermented with most of the representative strains was high in quality, exhibiting relatively high viscosity, moderate acidity, good sensory quality, and high counts of viable LAB. Fermented milk of E. durans SCA16 and L. fermentum SCA52 achieved the highest scores for overall sensory quality. Most strains displayed antimicrobial activity against at least 1 of 9 spoilage microorganisms. Lactic acid was the main factor inhibiting the growth of spoilage bacteria, and $\mathrm{H}_{2} \mathrm{O}_{2}$ was also inhibitory to some extent. Excluding the influence of acid and $\mathrm{H}_{2} \mathrm{O}_{2}$, strains SCA52 (L. fermentum) and SCA7 (Lactobacillus plantarum) were antagonistic against some of the indicators, suggesting that the 2 strains may produce a bacteriocin-like substance. Therefore, the development of superior strains isolated from Xueo to ferment milk with similar flavor and texture to Xueo is expected.

Key words: fermentation characteristic, lactic acid bacteria, Xueo, fermented yak milk

\section{INTRODUCTION}

Fermented dairy products have been popular for thousands of years in Tibetan regions of western Sichuan, China. Xueo is a homemade, viscous, fermented yogurt-like food prepared with yak milk, the main breeds of which are the Maiwa yak in Aba Prefecture

Received January 31, 2011.

Accepted November 14, 2011.

${ }^{1}$ Corresponding authors: zhangxiaopingphd@126.com and cai@ affrc.go.jp and the Jiulong yak in Ganzi Prefecture. Given the special characteristics of Xueo and the complex environmental factors characterizing this region, such as low temperatures (annual mean temperature $<8^{\circ} \mathrm{C}$ ), high elevation (mean 3,500 m), low oxygen levels, low atmospheric pressure, and lengthy sunlight radiation periods, the unique microbial resources in Xueo merit investigation (Zhang et al., 2008).

The traditional technique for the production of Xueo is very simple. The milk is boiled for $10 \mathrm{~min}$, cooled to about $30^{\circ} \mathrm{C}$, and then placed in a container. A small amount of previously produced Xueo is added to the container as a starter, and the mixture is incubated in a warm location $\left(\sim 30^{\circ} \mathrm{C}\right)$ until it curdles. The end product has a unique flavor along with a smooth and viscous texture, and does not deteriorate when stored at room temperature for up to $10 \mathrm{~d}$. Xueo is often consumed directly or mixed with honey or sugar. This delicious and readily preserved food has been produced and consumed for thousands of years in the minority prefectures of China, such as Tibet, Sinkiang, and Inner Mongolia, and in the Himalayan regions of India, Nepal, and Bhutan (Dewan and Tamang, 2006).

Currently, starters containing mainly Lactobacillus bulgaricus and Streptococcus thermophilus are used widely to improve fermentation quality in the industrial production of yogurt. However, the use of these starters limits the organoleptic variation of the end products (Leroy and Vuyst, 2004). Thus, this research sought to contribute to the selection and application of a new starter with desirable qualities based on traditional fermented milk.

The purpose of this study was to identify and screen the lactic acid bacteria (LAB) isolated from Xueo made in the western Sichuan Plateau, and to evaluate the use of these LAB species in a starter culture for producing Xueo-flavored yogurt.

\section{MATERIALS AND METHODS}

\section{LAB Isolation}

The LAB used in this study were isolated from 12 Xueo samples collected from Ganzi and Aba Tibetan 
Autonomous Prefectures, Sichuan, China, in August 2008. All samples were transported to the laboratory in an ice box and analyzed immediately.

Four diverse media and cultural conditions were applied. de Man, Rogosa, and Sharpe (MRS) agar (De Man et al., 1960), Elliker agar (Elliker et al., 1956), KF Streptococcus agar (Devriese et al., 1983), and Leuconostoc selective medium (LUSM; Benkerroum et al., 1993) were used to culture lactobacilli at $37^{\circ} \mathrm{C}$, lactococci at $30^{\circ} \mathrm{C}$, enterococci at $37^{\circ} \mathrm{C}$, and leuconostocs at $25^{\circ} \mathrm{C}$, respectively. Ten grams of each sample was added to $90 \mathrm{~mL}$ of sterile physiological saline and homogenized for $10 \mathrm{~min}$. One milliliter of each sample was aspirated into different media to isolate the corresponding LAB. All pure isolates were stored at $-75^{\circ} \mathrm{C}$ in nutrient broth (Difco, Sparks, MD) supplemented with 10\% dimethyl sulfoxide (vol/vol).

The Gram stain status, morphological characteristics, and catalase activity of the isolates were determined after incubation on MRS agar for $24 \mathrm{~h}$. The gram-positive and catalase-negative strains were subjected to amplified ribosomal DNA restriction analysis (ARDRA).

\section{Amplified Ribosomal DNA Restriction Analysis}

DNA Extraction. Strains were harvested for DNA extraction and purification after cultivating them in MRS broth at $37^{\circ} \mathrm{C}$ for $18 \mathrm{~h}$. Total DNA was extracted using the Bacterial Genomic DNA Extraction kit (Tiangen Co. Ltd., Beijing, China). The DNA concentration and quality were determined with a spectrophotometer.

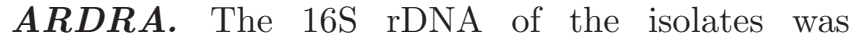
amplified by PCR using the primers P1 (8-27f: 5'-AGAGTTTGATCCTGGCTCAG-3') and P2 (1520-1541r: 5'-AAGGAGGTGATCCAGCCGCA-3') (Wilmotte et al., 1993). The amplified products were digested with 4 restriction endonucleases: HaeIII, MspI, HinfI, and TaqI (MBI Fermentas, Vilnius, Lithuania). A mixture including $0.5 \mu \mathrm{L}$ of enzyme $(10 \mathrm{IU} / \mu \mathrm{L}), 2 \mu \mathrm{L}$ of buffer, $4 \mu \mathrm{L}$ of PCR amplified product, and $3.5 \mu \mathrm{L}$ of distilled water was digested for $3 \mathrm{~h}$ at $37^{\circ} \mathrm{C}$ ( TaqI at $65^{\circ} \mathrm{C}$ ). Digested fragments were separated on $3 \%$ agarose gels. The NT-SYS program (Applied Biostatistics Inc., New York, NY) was used to calculate the distance and the unweighted pair group method with arithmetic mean (UPGMA) method was used to cluster.

\section{S rDNA Sequence Analysis}

Eleven representative isolates were chosen to determine the $16 \mathrm{~S}$ rDNA gene sequences using an ABI 3730 sequencer (Applied Biosystems, Foster City, CA). The 16S rDNA nucleotide sequence data were deposited in the DDBJ/EMBL/GenBank nucleotide sequence data- bases with the serial accession numbers AB602930 to AB602939 and AB605428 for the strains SCA2, SCA17, SCA16, SCA5, SCA36, SCA22, SCA34, SCA7, SCA39, SCA52, and SCA33, respectively. Multiple sequences were assembled and aligned with the Clustal W program (Thompson et al., 1994). Type strain sequences were compared using the BLAST tool in the GenBank database (http://www.ncbi.nlm.nih.gov/blast/Blast. cgi). A phylogenetic tree was constructed using MEGA 4.0 under the Kimura 2-parameter model (Tamura et al., 2007) and bootstrapped with 1,000 replicates.

\section{atpA Gene Analysis}

The atp $A$ genes of the isolates were amplified using the primers atpA-1 (5'-TAYRTYGGKGAYGGDATYGC- $\left.3^{\prime}\right)$ and atpA-2 (5'-CCRCGRTTHARYTTH GCYTG-3'; Naser et al., 2005) and amplifications were checked on $1 \%$ agarose gels. The gene fragments (about $1,100 \mathrm{bp}$ ) were cut and then purified with a UNIQ10 Spin kit (Sangon, Shanghai, China), and $10 \mu \mathrm{L}$ of purified product was cloned into pGEM-T (Takara Bio Inc., Shiga, Japan) according to the manufacturer's instructions. Positive clones were sequenced (Sangon). The accession numbers of the atp $A$ gene sequences are AB618965 to AB618969 for the strains SCA2, SCA17, SCA16, SCA7, and SCA39. Phylogenetic trees based on the $\operatorname{atp} A$ genes were constructed using the same method as that used for the $16 \mathrm{~S}$ rDNA sequence analysis.

\section{Phenotypic Features}

Representative isolates of the different groups in the ARDRA dendrogram were chosen to determine the phenotypic features including morphological, physiological, and biochemical characteristics. Gas production from glucose and growth in 3.0 and $6.5 \% \mathrm{NaCl}$ was tested in MRS broth at $30^{\circ} \mathrm{C}$ for $48 \mathrm{~h}$. Growth at different temperatures, including $5,10,45$, and $50^{\circ} \mathrm{C}$ was observed after incubating the isolates in MRS broth for 7 d. Growth at $\mathrm{pH}$ 3.0, 3.5, 4.0, 7.0, and 9.6 was detected after incubating the isolates in MRS broth at $30^{\circ} \mathrm{C}$ for 7 d (Yang et al., 2010).

\section{Antimicrobial Activity}

The antimicrobial activities of the isolates were determined according to the agar well diffusion assay described by Vinderola et al. (2002). Potato dextrose agar and beef extract peptone agar were used to determine antifungal activity and antibacterial activity, respectively. Nine food spoilage and pathogenic microorganisms, including Escherichia coli ATCC 35218, Staphylococcus aureus ATCC 25923, Bacillus subtilis CMCC 
63501, Bacillus megaterium CICC 23692, Pseudomonas aeruginosa ATCC 27853, Micrococcus luteus CICC 10209, Saccharomyces cerevisiae CICC 31482, Aspergillus flavus CICC 2003, and Rhizopus oryzae CICC 3073 were used as the indicator microbes. The LAB cell-free supernatants were neutralized with $\mathrm{NaOH}$ and incubated at $80^{\circ} \mathrm{C}$ for $15 \mathrm{~min}$ to examine inhibition of $\mathrm{pH}$ and $\mathrm{H}_{2} \mathrm{O}_{2}$ on the indicators (Nazef et al., 2008). The bacterial inhibition zone was recorded after incubating the bacteria at $37^{\circ} \mathrm{C}$ for $24 \mathrm{~h}$ and fungi at $28^{\circ} \mathrm{C}$ for 48 to $72 \mathrm{~h}$.

\section{Fermentation Characteristics of Representative Strains in Fermented Milk}

Fermentation Milk Manufacture. Reconstituted milk with $12 \%$ TS content was used to make yogurt. Milk was heated at $95^{\circ} \mathrm{C}$ for $10 \mathrm{~min}$, cooled to $30^{\circ} \mathrm{C}$ (similar fermentation temperature to that of Xueo), inoculated with $2 \%$ starter culture, which was subcultured 20 times in milk with a single strain, and then incubated at $30^{\circ} \mathrm{C}$. The incubation ended when the samples reached $\mathrm{pH} 4.7$, and fermentation time was recorded. The samples were immediately cooled and stored at $4^{\circ} \mathrm{C}$ for $12 \mathrm{~h}$ to finish maturation.

Fermentation Characteristics. One gram of each sample was serially diluted in $9 \mathrm{~mL}$ of sterile physiological water, and a $1-\mathrm{mL}$ dilution $\left(10^{-5}-10^{-7}\right)$ was used to determine viable LAB counts according to the description of Terzic-Vidojevic et al. (2007). Acidity was determined by titration with $0.1 \mathrm{~N} \mathrm{NaOH}$ using phenolphthalein as the indicator and the results were expressed as Thorner degrees $\left({ }^{\circ} \mathrm{T}\right)$. Viscosity was determined at $5^{\circ} \mathrm{C}$ with an NDJ-1 rotational viscometer (Shanghai Changji Geological Instruments Co. Ltd., Shanghai, China) based on the instruction manual. All tests were performed in triplicate for $1,5,10,15$, and $20 \mathrm{~d}$. Flavor compounds were analyzed after storage at $4^{\circ} \mathrm{C}$ for $24 \mathrm{~h}$. The lactate and acetate concentrations in the yogurt were determined by HPLC according the method described by Zhang et al. (2008). Diacetyl and acetaldehyde contents were determined based on the method described by Ao et al. (2005).

Sensory Evaluation. Ten panelists (age, 18-52 yr) were selected and trained for $8 \mathrm{~h}$ to evaluate plain yogurt based on International Organization for Standardization methods (ISO, 1993, 2008). Panelists evaluated the characteristics of the fermented yogurt with different LAB strains using a 10-point scale (Hashim et al., 2009): appearance $(1=$ no curd; $10=$ smooth yogurt gel without whey), texture $(1=$ water; $10=$ plain yogurt with $15 \% \mathrm{NDM})$, flavor $(1=$ yogurt with unsatisfactory odor; $10=$ yogurt with satisfactory, fer- mented flavor $)$, and overall quality $(1=$ poor quality; $10=$ excellent quality).

Statistical Analyses. Data on fermentation characteristics and sensory quality of yogurt fermented with representative strains were subjected to ANOVA, and the Tukey test was used to identify differences $(P<$ 0.05 ) between means using the GLM procedure of SAS (SAS Institute Inc., Cary, NC).

\section{RESULTS}

\section{Xueo Samples and LAB Isolation}

Table 1 lists the LAB isolated from Xueo. All strains were collected in August 2008 from sites on the western Sichuan Plateau between the elevations of 1,350 and $3,560 \mathrm{~m}$, with local daily temperatures fluctuating from 7 to $25^{\circ} \mathrm{C}$. The $\mathrm{pH}$ values of the samples ranged from 3.6 to 4.2 .

Colonies $(\mathrm{n}=109)$ that differed in color, shape, and transparency were selected from 4 media. Fifty-three strains were identified preliminarily as LAB on the basis of gram positivity, catalase negativity, and lactic acid production. These strains were collected from MRS (n $=23), \mathrm{KF}$ Streptococcus $(\mathrm{n}=20)$, Elliker $(\mathrm{n}=7)$, and Leuconostoc selective $(\mathrm{n}=3)$ media.

\section{ARDRA}

Figure 1 presents a comparison of ARDRA profiles based on the restriction fragments of $16 \mathrm{~S}$ rRNA by MspI, HinfI, TaqI, and HaeIII. All isolates were divided into 11 restriction patterns ( $\mathrm{C} 1$ to $\mathrm{C} 11$ ) according to dissimilar restriction fragments. In contrast to MspI, HinfI, and TaqI, HaeIII achieved relatively higher discrimination in the classification of the $16 \mathrm{~S}$ rRNA of the isolates. Representative strains SCA2 (n $=13), \operatorname{SCA} 17(\mathrm{n}=8), \operatorname{SCA} 16(\mathrm{n}=3), \operatorname{SCA} 36(\mathrm{n}=$ $1), \operatorname{SCA} 5(\mathrm{n}=2), \operatorname{SCA} 52(\mathrm{n}=12), \operatorname{SCA} 7(\mathrm{n}=2)$, SCA39 $(\mathrm{n}=2)$, SCA34 $(\mathrm{n}=6), \operatorname{SCA} 33(\mathrm{n}=3)$, and SCA22 $(n=1)$ from different clusters were selected for further study.

\section{$16 S$ rRNA Sequence Analysis}

Figures 2 and 3 present phylogenetic trees that give the relative positions of the isolates. Phylogenetic analysis divided the representative strains into 6 groups (A to F). Groups A (SCA2, SCA17, and SCA16) and B (SCA36 and SCA5) were assigned to the genus Enterococcus. The $16 \mathrm{~S}$ rRNA sequences in group A strains showed more than $99.2 \%$ similarity to Enterococcus hirae and Enterococcus durans. Strains in 
Table 1. Lactic acid bacteria isolated from Xueo fermented yak milk and their collections

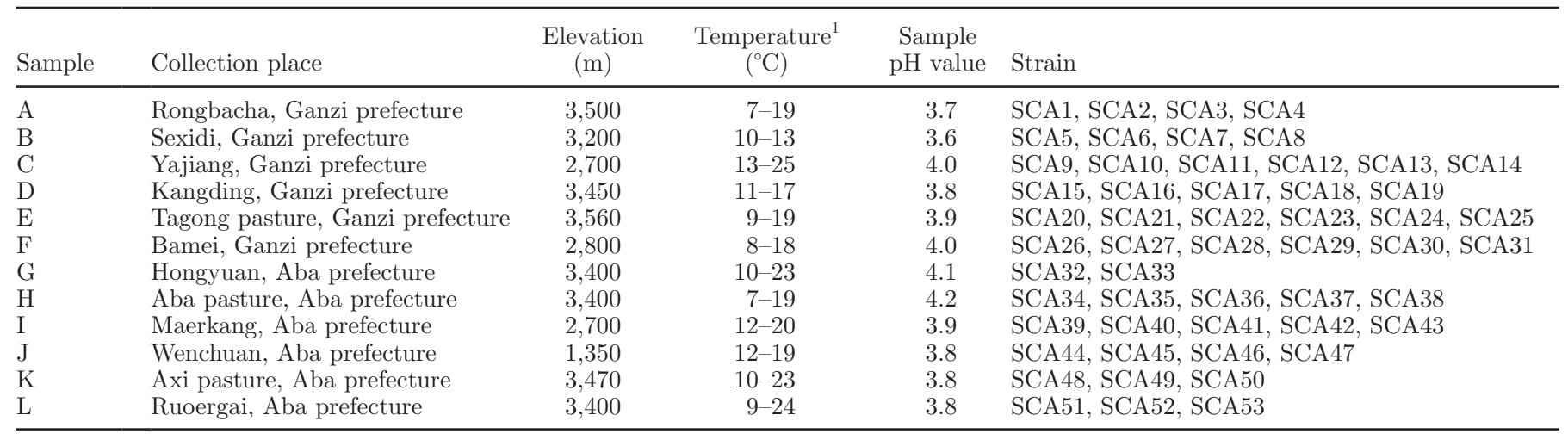

${ }^{1}$ Local daily temperature of sample collection in August 2008.

group B were closely related to Enterococcus faecalis. The single strain (SCA22) in Group F was placed in the genus Streptococcus and showed the closest relationship with Strep. thermophilus. Strains in groups $\mathrm{C}, \mathrm{D}$, and E were assigned to the genus Lactobacillus. Group C strain SCA52 was grouped with Lactobacillus fermentum. Strains SCA7 and SCA39 in group D showed equal similarity to Lactobacillus plantarum and Lactobacillus pentosus. The $16 \mathrm{~S}$ rRNA sequence of strain SCA7 showed $99.4 \%$ similarity to L. plantarum and L. pentosus, and that of strain SCA39 showed $100 \%$ similarity to L. plantarum and $99.9 \%$ similarity to L. pentosus. Strains SCA33 and SCA34 in group E were closely related to Lactobacillus paracasei on the phylogenetic tree.

\section{atpA Gene Sequence Analysis}

Figure 4 shows a phylogenetic tree based on the atp $A$ gene sequences of the $E$. durans group. Three strains (SCA2, SCA16, and SCA17) in group A were closely related to E. durans. They showed more than $99.7 \%$ atp $A$ gene-sequence similarity to $E$. durans and less than $90.9 \%$ similarity to the closest species, E. hirae. Figure 5 shows a phylogenetic tree based on the atp $A$ gene sequences of the L. plantarum group. Strains SCA7 and SCA39 in group D formed a distinct cluster with $L$. plantarum and their atpA gene sequences showed more than $99 \%$ similarity to L. plantarum, less than $96 \%$ similarity to Lactobacillus paraplantarum, and $92 \%$ similarity to L. pentosus.

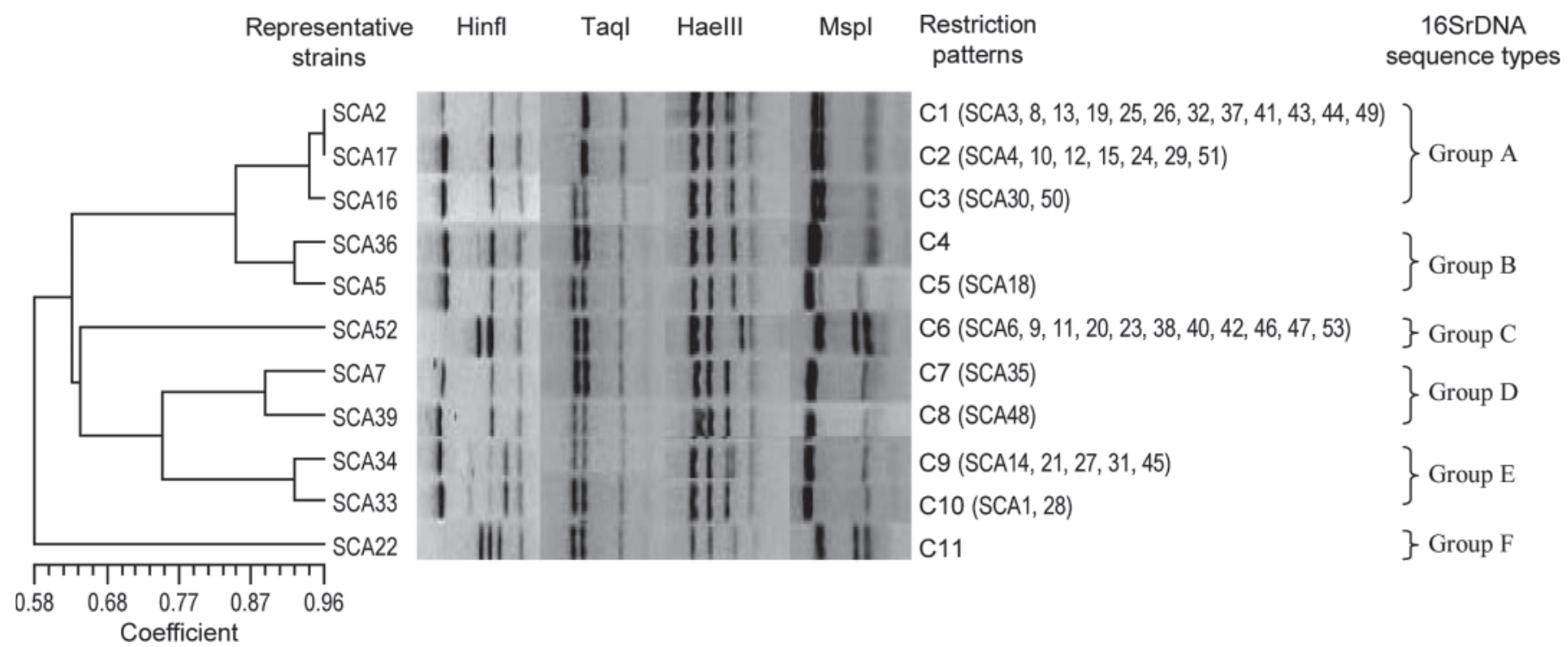

Figure 1. Comparison of amplified ribosomal DNA restriction analysis (ARDRA) profiles based on the restriction fragments of 16S rDNA by HaeIII, MspI, HinfI, and TaqI. The dendrogram was constructed by the unweighted pair group method with arithmetic mean (UPGMA). Only the representative strains of each cluster are listed. 


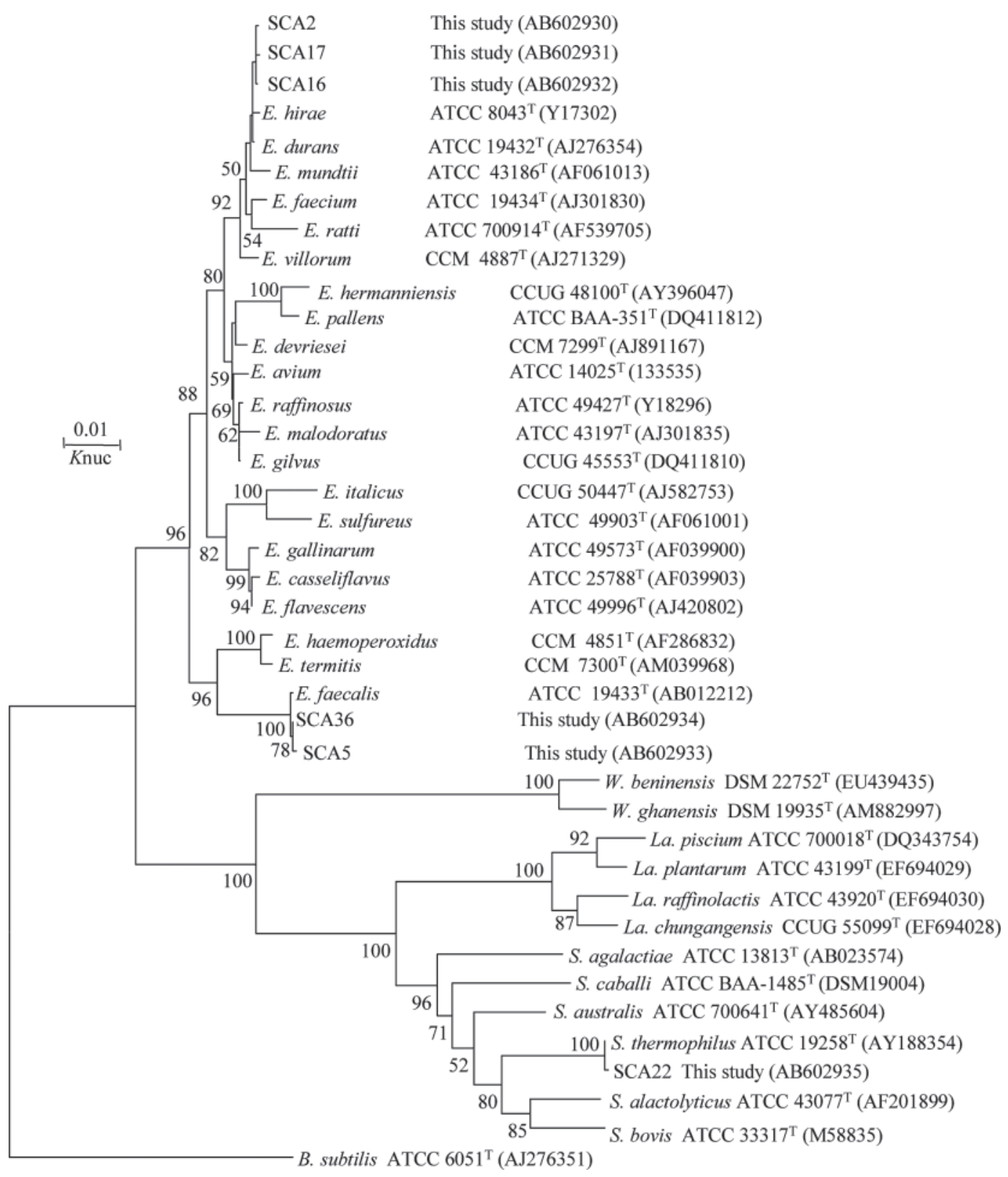

Figure 2. Phylogenetic tree showing the relative position of representative strains SCA2, SCA17, SCA16, SCA36, SCA5, and SCA22 isolated from Xueo based on the $16 \mathrm{~S}$ rDNA sequences. Bootstrap values (1,000 replicates) are indicated at branch nodes. Bacillus subtilis was used as an outgroup. La. $=$ Lactococcus; $B .=$ Bacillus; $S .=$ Streptococcus; E. $=$ Enterococcus $; W .=$ Weissella; Knuc $=$ nucleotide substitution rate.

\section{Phenotypic Properties}

Tables 2 and 3 list the morphological, physiological, and biochemical characteristics of the representative strains isolated from Xueo. All strains grew in 3.0\% $\mathrm{NaCl}$, at $\mathrm{pH} 4.0$ to 7.0 , and at 10 to $45^{\circ} \mathrm{C}$. Strains in groups $\mathrm{A}, \mathrm{B}$, and $\mathrm{F}$ were homofermentative cocci that formed L-lactic acid and did not produce gas from glucose. Strains in groups A and B grew in $6.5 \% \mathrm{NaCl}$, and at $\mathrm{pH}$ 9.6, but those in group $\mathrm{F}$ did not. Strains in groups $\mathrm{D}$ and $\mathrm{E}$ were homofermentative rods that did not produce gas from glucose. Strains in group D formed DL-lactic acid and those in group E formed Llactic acid. Strains in group $\mathrm{C}$ were heterofermentative rods that produced gas from glucose, formed DL-lactic acid, and grew in $6.5 \% \mathrm{NaCl}$ and at $\mathrm{pH} 3.0$.

\section{Antimicrobial Activities}

Table 3 shows the antimicrobial activities of the representative strains isolated from Xueo against food 


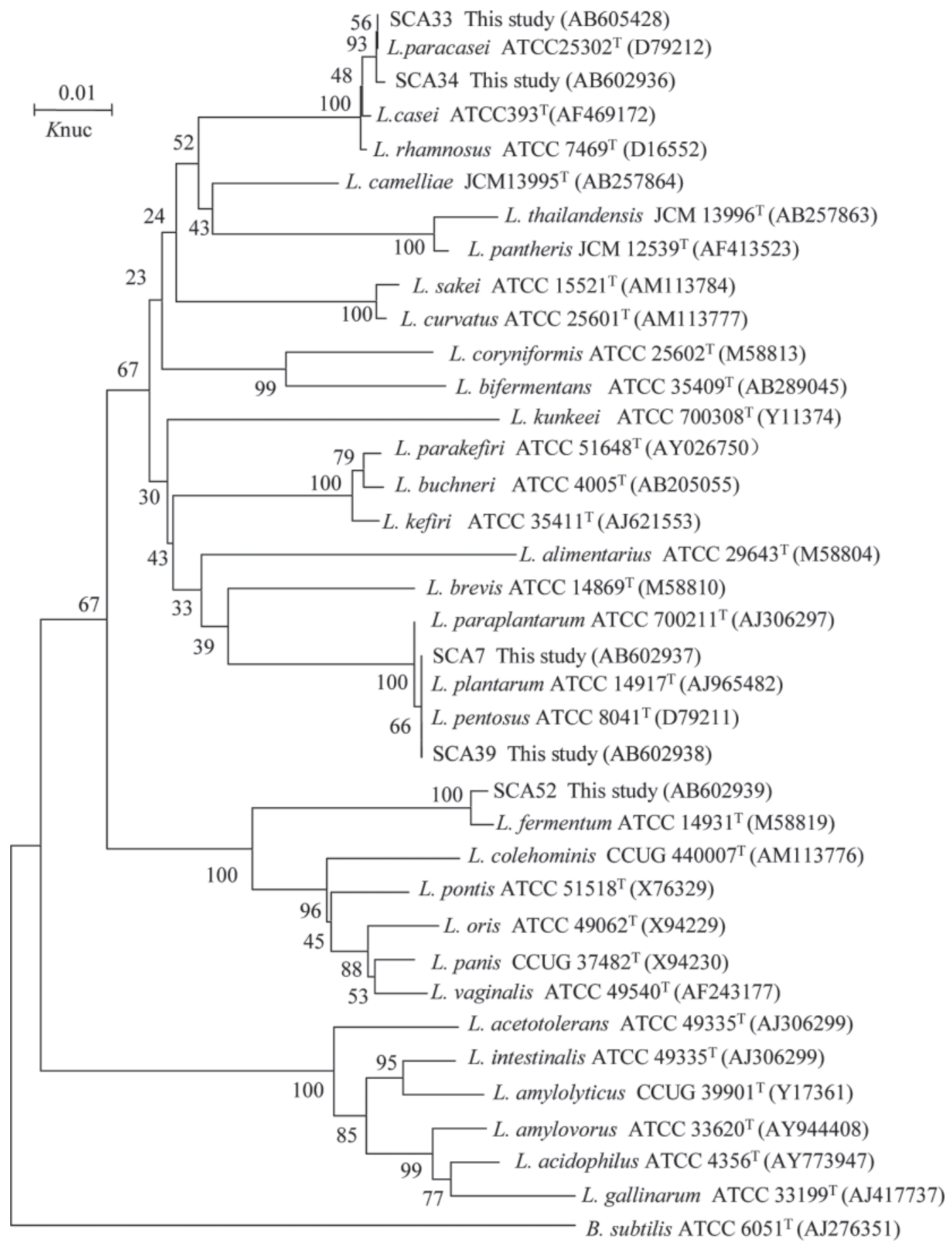

Figure 3. Phylogenetic tree showing the relative position of representative strains SCA33, SCA34, SCA7, SCA39, and SCA52 isolated from Xueo based on the 16S rDNA sequences. Bootstrap values (1,000 replicates) are indicated at branch nodes. Bacillus subtilis was used as an outgroup. L. = Lactobacillus; $B .=$ Bacillus; Knuc $=$ nucleotide substitution rate.

spoilage and pathogenic microorganisms. All representative strains showed antimicrobial activity against at least 1 of the 9 indicator microbes, but no strain inhibited undesirable fungi (Saccharomyces cerevisiae, Aspergillus flavus, and Rhizopus oryzae). The untreated cell-free supernatants of half of the representative strains effectively inhibited B. megaterium, B. subtilis, and $M$. luteus. The SCA52 (L. fermentum), SCA7 ( $L$. plantarum), and SCA34 (L. paracasei) strains showed stronger inhibition $(80 \%)$ of the indicator bacteria. 


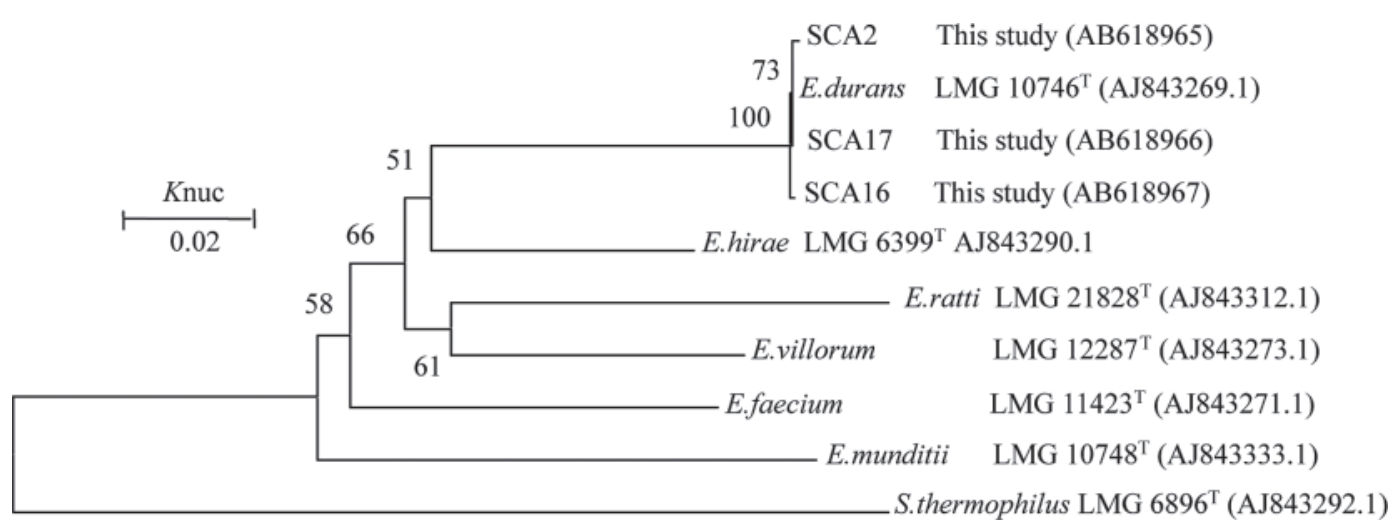

Figure 4. Neighbor-joining phylogenetic tree based on the atp A gene sequences of the Enterococcus durans group. Bootstrap values (1,000 replicates) are indicated at branch nodes. Streptococcus thermophilus was used as an outgroup. S. = Streptococcus; E. $=$ Enterococcus; Knuc $=$ nucleotide substitution rate.

Heating at $80^{\circ} \mathrm{C}$ for 10 min decreased the antibacterial activity of strains SCA16, SCA5, SCA39, and SCA34, and neutralization with $\mathrm{NaOH}$ terminated the antibacterial activity of most strains. However, the SCA52 strain continued to effectively inhibit E. coli, Staph. aureus, and $P$. aeruginosa, and the SCA7 strain exhibited antibacterial activity against Staph. aureus, B. subtilis, and $M$. luteus after heating and neutralization.

\section{Fermentation Characteristics}

Table 4 lists the fermentation characteristics of representative strains. Yogurts fermented with isolates from different groups differed significantly $(P<0.05)$ in fermentation characteristics, viable LAB counts, and sensory quality. Fermentation times ranged from 3.17 to $5.48 \mathrm{~h}$. Acidity ranged from 63.40 to $87.63^{\circ} \mathrm{T}$, and strains in group D (L. plantarum) produced more lactic acid $\left(>80^{\circ} \mathrm{T}\right)$ than other strains. In this experiment,
Lactobacillus strains showed stronger post-acidification ( 8.72 to $13.87^{\circ} \mathrm{T}$ ) than Enterococcus (5.8 to $9.7^{\circ} \mathrm{T}$ ) and Streptococcus $\left(8.68^{\circ} \mathrm{T}\right)$ strains. Ninety percent of samples had high viscosity $\left(>10^{3} \mathrm{mPa} \cdot \mathrm{s}\right)$. Yogurt fermented with SCA2 (E. durans) acquired the highest viscosity and that fermented with SCA33 (L. paracasei) showed the lowest viscosity. The average viable $\mathrm{LAB}$ counts of samples remained high $\left(>10^{7} \mathrm{cfu} / \mathrm{g}\right)$. With regard to sensory quality, strains in group A achieved the highest scores for appearance and texture, whereas strain SCA52 in group C achieved a higher score for flavor. Strains SCA16 and SCA52 had higher (>8.0) scores for overall sensory quality based on smooth appearance, viscous texture, and satisfying flavor.

\section{DISCUSSION}

Following the appearance of domesticated yaks in Tibet, fermented yak milk became an important daily

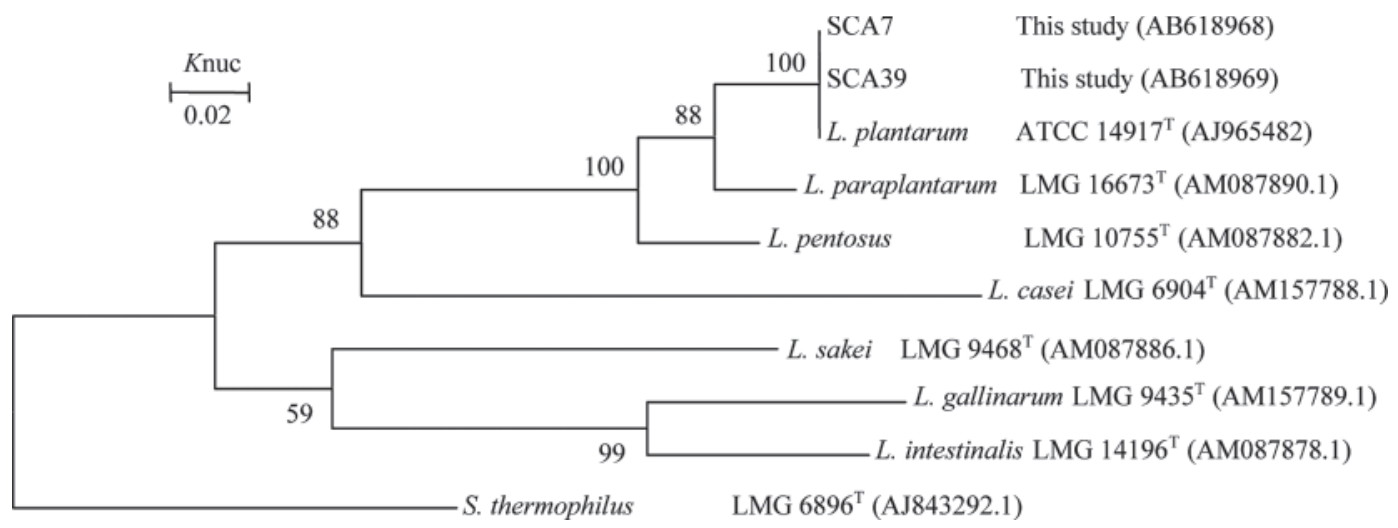

Figure 5. Neighbor-joining phylogenetic tree based on the atpA gene sequences of the Lactobacillus plantarum group. Bootstrap values (1,000 replicates) are indicated at branch nodes. Streptococcus thermophilus was used as an outgroup. S. $=$ Streptococcus; L. $=$ Lactobacillus; Knuc $=$ nucleotide substitution rate. 
Table 2. Characteristics of representative strains ${ }^{1}$

\begin{tabular}{|c|c|c|c|c|c|c|c|c|c|c|c|}
\hline \multirow[b]{2}{*}{ Characteristic } & \multicolumn{3}{|c|}{ Group A } & \multicolumn{2}{|c|}{ Group B } & \multirow{2}{*}{$\frac{\text { Group C }}{\text { SCA52 }}$} & \multicolumn{2}{|c|}{ Group D } & \multicolumn{2}{|c|}{ Group E } & \multirow{2}{*}{$\frac{\text { Group F }}{\text { SCA22 }}$} \\
\hline & SCA2 & SCA17 & SCA16 & SCA36 & SCA5 & & SCA7 & SCA39 & SCA34 & SCA33 & \\
\hline No. of isolates & 13 & 8 & 3 & 1 & 2 & 12 & 2 & 2 & 3 & 6 & 1 \\
\hline Shape & Cocci & Cocci & Cocci & Cocci & Cocci & Rod & Rod & Rod & Rod & Rod & Cocci \\
\hline Gram stain & + & + & + & + & + & + & + & + & + & + & + \\
\hline Catalase reaction & - & - & - & - & - & - & - & - & - & - & - \\
\hline Gas from glucose & - & - & - & - & - & + & - & - & - & - & - \\
\hline Fermentation type & Homo & Homo & Homo & Homo & Homo & Hetero & Homo & Homo & Homo & Homo & Homo \\
\hline Optical form of lactate & $\mathrm{L}(+)$ & $\mathrm{L}(+)$ & $\mathrm{L}(+)$ & $\mathrm{L}(+)$ & $\mathrm{L}(+)$ & DL & DL & DL & $\mathrm{L}(+)$ & $\mathrm{L}(+)$ & $\mathrm{L}(+)$ \\
\hline \multicolumn{12}{|l|}{ Growth at temperature: } \\
\hline $5^{\circ} \mathrm{C}$ & $\mathrm{w}$ & $\mathrm{w}$ & $\mathrm{w}$ & $\mathrm{w}$ & $\mathrm{w}$ & $\mathrm{w}$ & $\mathrm{w}$ & $\mathrm{w}$ & - & - & - \\
\hline $10^{\circ} \mathrm{C}$ & + & + & + & + & + & + & + & + & $\mathrm{w}$ & $\mathrm{w}$ & $\mathrm{w}$ \\
\hline $45^{\circ} \mathrm{C}$ & + & $\mathrm{w}$ & + & + & $\mathrm{w}$ & $\mathrm{w}$ & + & + & $\mathrm{w}$ & + & + \\
\hline $50^{\circ} \mathrm{C}$ & - & - & - & - & - & - & - & - & - & - & $\mathrm{w}$ \\
\hline \multicolumn{12}{|l|}{ Growth in $\mathrm{NaCl}$ : } \\
\hline $3.00 \%$ & + & + & + & + & + & + & + & + & + & + & + \\
\hline $6.50 \%$ & + & $\mathrm{w}$ & + & + & + & + & + & + & - & - & - \\
\hline \multicolumn{12}{|l|}{ Growth at $\mathrm{pH}$ : } \\
\hline 3.0 & - & - & - & $\mathrm{w}$ & - & + & + & + & - & + & - \\
\hline 3.5 & $\mathrm{w}$ & - & - & $\mathrm{w}$ & - & + & + & + & + & + & $\mathrm{w}$ \\
\hline 4.0 & + & + & + & + & + & + & + & + & + & + & + \\
\hline 7.0 & + & + & + & + & + & + & + & + & + & + & + \\
\hline 9.6 & + & + & + & + & + & - & - & - & - & - & - \\
\hline
\end{tabular}

${ }^{1}+=$ positive; $\mathrm{w}=$ weakly positive $;-=$ negative; Homo $=$ homofermentation; Hetero $=$ heterofermentation. 


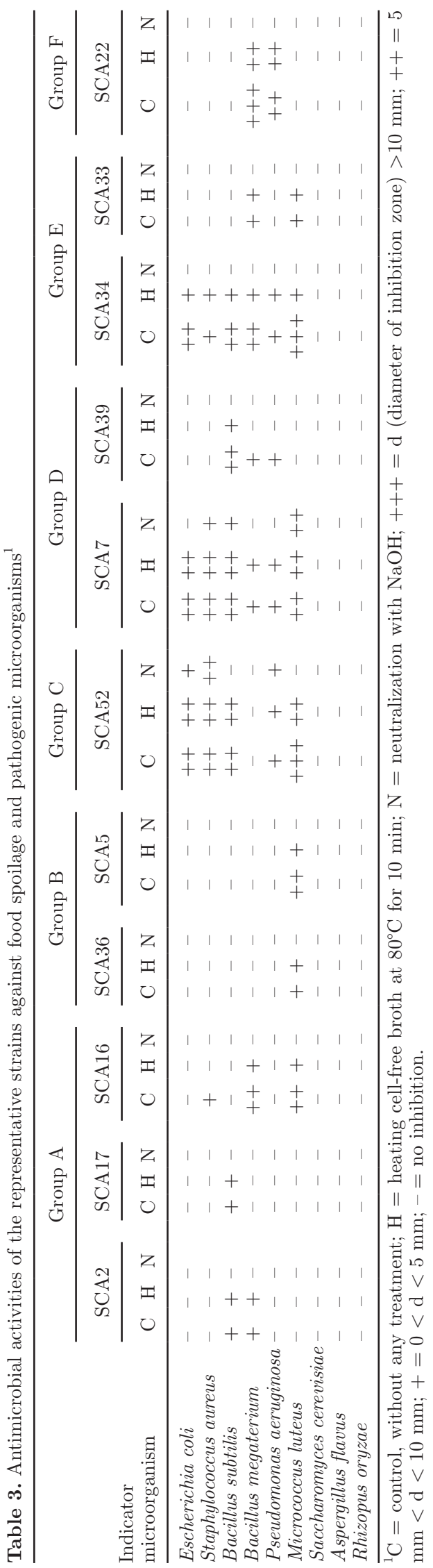

food product in this region and has remained such for thousands of years (Airidengcaicike, 2010). To store and preserve excess yak milk, Tibetans follow the traditional and ancient method of making Xueo. The fermentation process depends on naturally occurring microorganisms in yak milk. The indigenous microbiota of this environment has been preserved in numerous subcultures and provides the distinct flavor and viscous texture of Xueo. No previous study has intensively investigated the characteristics of LAB isolated from Chinese Xueo. These microflora were described in detail due to the high fermentation quality and nutritive value of the fermented milk.

In the present study, all strains were analyzed using the ARDRA method. Then, the representative strains were selected by different $16 \mathrm{~S}$ rDNA restriction patterns digested by HaeIII, MspI, HinfI, and TaqI (Figure 1). The LAB strains isolated from Xueo were divided into 11 clusters by ARDRA and 6 species were identified by $16 \mathrm{~S}$ rDNA and atp $A$ gene sequence analyses. Phylogenetic analysis of $16 \mathrm{~S}$ rDNA sequences identified strains in groups B, E, and F as L. fermentum, E. faecalis, and Strep. thermophilus, respectively. Strains in group A showed equal similarity to $E$. hirae and $E$. durans on the phylogenetic tree and over $99.2 \% 16 \mathrm{~S}$ rDNA sequence similarity to the 2 species. Previous reports have determined that $16 \mathrm{~S}$ rDNA sequences have limited discriminating power for identifying the species in the E. durans group (E. durans, E. hirae, Enterococcus villorum, Enterococcus munditii, and Enterococcus faecium), and complicated methods, such as amplified fragment length polymorphism, pulsedfield gel electrophoresis, and transfer DNA-PCR, have been used as alternatives (Devriese et al., 2002). Naser et al. (2005) distinguished these species by comparing atp $A$ gene sequences. In this study, 6 closely related Enterococcus species were categorized distinctively (Figure 4) by phylogenetic analysis of atp $A$ genes and the strains in group A were identified exclusively as E. durans. Strains in group D formed a cluster with L. plantarum and L. pentosus, and their $16 \mathrm{~S}$ rRNA sequences showed over $99.4 \%$ similarity to the 2 species. L. plantarum, L. pentosus, and L. paraplantarum have closely related genotypes and highly similar phenotypes, complicating their discrimination by the conventional method (Torriani et al., 2001). In the present study, atpA gene sequence analysis unambiguously identified the strains of group D as L. plantarum. Following the $16 \mathrm{~S}$ rDNA analysis, strains SCA33 and SCA34 clustered together, and the typic strain $L$. paracase $i$ was the most closely related species, which was supported by more than $99.5 \%$ similarity in the $16 \mathrm{~S}$ rRNA gene sequence analysis. The other typic strains Lactobacillus casei and Lactobacillus rhamno- 
Table 4. Fermentation characteristics of representative strains in fermented milk ${ }^{1}$

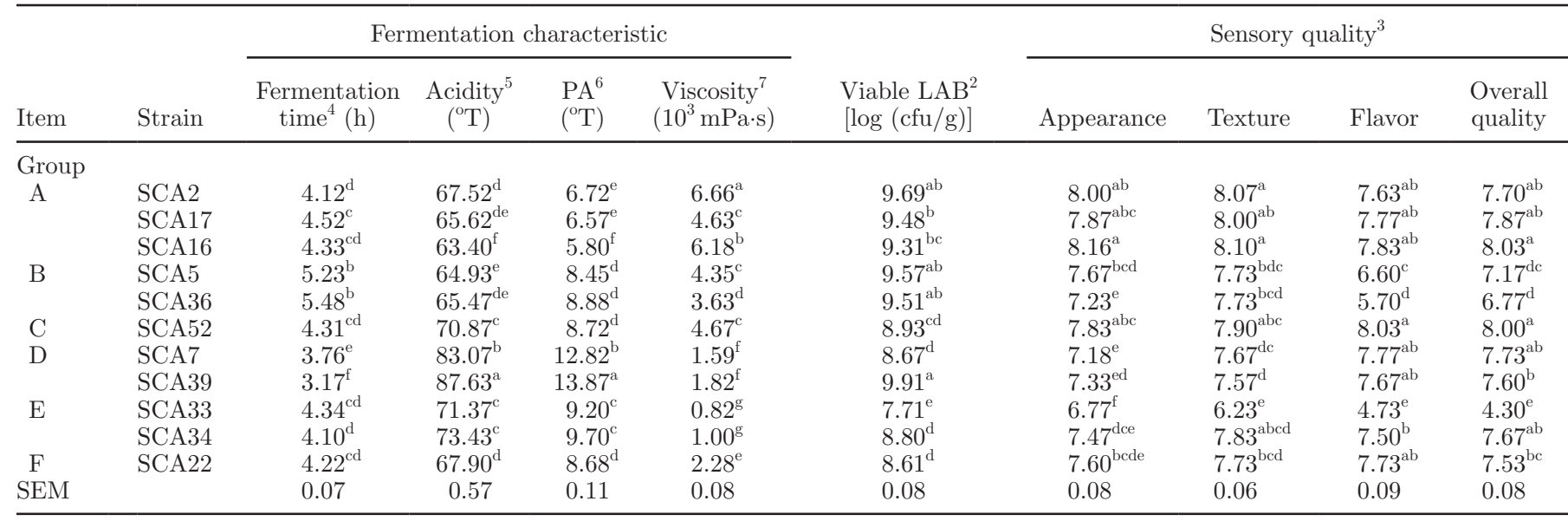

${ }^{a-g}$ Means in the same column with different superscript letters are significantly different $(P<0.05)$.

${ }^{1}$ Means of 3 replicates.

${ }^{2}$ Viable lactic acid bacteria (LAB) was the average value for $20 \mathrm{~d}$.

${ }^{3} 1=$ poor quality to $10=$ excellent quality.

${ }^{4}$ The time from inoculation to $\mathrm{pH} 4.7$.

${ }^{5}$ Acidity was determined after storing at $4^{\circ} \mathrm{C}$ for $12 \mathrm{~h}$.

${ }^{6} \mathrm{PA}=$ post-acidification, the increased acidity during storage at $5^{\circ} \mathrm{C}$ for $20 \mathrm{~d}$, expressed as Thorner degrees $\left({ }^{\circ} \mathrm{T}\right)$.

${ }^{7}$ Viscosity was the average value for $20 \mathrm{~d}$.

sus showed similarities of $<98.9 \%$. Therefore, strains in group C belonged to L. paracasei.

The dominant LAB strains in naturally fermented milk were Lactococcus lactis in Rome (Zamfir, et al., 2006), L. paracasei and L. lactis in Himalayan ethnic fermented milk products (Dewan and Tamang, 2007), and Leuconostoc mesenteroides and E. faecium in Serbia (Jokovic et al., 2008). In our study, the dominant LAB strains in Xueo were E. durans $(45.3 \%), L$. fermentum (22.6\%), and L. paracasei (17.0\%). E. faecalis, L. plantarum, and Strep. thermophilus were present in lower frequencies. Different raw materials and environmental conditions have contributed to the unique microflora in these fermented milks and have influenced the texture and flavor of the end products.

The acidity, texture, and sensory quality of fermented milk are strongly related to the starter culture. In this study, different species appeared to have distinct functions in fermented milk. Enterococci, especially E. durans, were isolated from almost all samples and produced yogurts with high score on appearance and texture. Previous studies have demonstrated that enterococci have numerous functions, such as taste formation through proteolysis, enterocin production to inhibit other bacteria, and the formation of viscous material to improve texture, which have led to their use in many food production applications (Foulquié Moreno et al., 2006). In this study, yogurts fermented with $E$. durans acquired high viscosity (Table 4 ), and this quality has been associated with the exopolysaccharide produced by LAB strains (Patrignani et al., 2006). Many papers have reported that exopolysaccharide enhances the texture and viscosity of products, improves their functional properties, and may protect cells against detrimental environmental conditions and phage infection (Broadbent et al., 2003; Purwandari et al., 2007). Exopolysaccharide may, thus, be one reason for the highly viscous texture of Xueo and its failure to deteriorate when stored at room temperature in its original environment for more than $10 \mathrm{~d}$. The dominant lactobacilli in Xueo were L. fermentum and L. paracasei. Although moderate acidity and weak post-acidification contribute to product stability and long shelf-life, most lactobacilli in fermented milk are characterized by relatively higher acidification rates and strong postacidification (St-Gelais et al., 2009). In this experiment, yogurts fermented with strains SCA52 (L. fermentum), SCA33 (L. paracasei), and SCA34 (L. paracasei) had appropriate acidity (70.87 to $73.43^{\circ} \mathrm{T}$ ) and weaker postacidification, which are important selection criteria for yogurt starter cultures (De Vuyst et al., 2003). Because it produced a more volatile organic aroma through heterofermentation, yogurt fermented with SCA52 achieved a high score for flavor. Yogurts fermented with the isolates in this study also maintained higher viable $\mathrm{LAB}$ counts during storage at $4^{\circ} \mathrm{C}$. Lactic acid bacteria have many beneficial effects on humans, such as balancing of intestinal flora and enhancement of the immune 
Table 5. Comparatively analyzed properties of Xueo, marketed yogurts, and the yogurts fermented with selected strains (average value $\pm \mathrm{SD}$ )

\begin{tabular}{|c|c|c|c|c|}
\hline Item & SCA52 & SCA16 & $\mathrm{Xueo}^{1}$ & Marketed yogurt ${ }^{2}$ \\
\hline \multicolumn{5}{|l|}{ Flavor compound } \\
\hline Lactate (g/100 g) & $0.87 \pm 0.12$ & $0.52 \pm 0.10$ & $0.93 \pm 0.23$ & $0.91 \pm 0.22$ \\
\hline Acetate $(\mathrm{g} / 100 \mathrm{~g})$ & $0.48 \pm 0.08$ & $0.24 \pm 0.11$ & $0.53 \pm 0.32$ & $0.13 \pm 0.10$ \\
\hline Acetaldehyde (mg/L) & $18.72 \pm 1.10$ & $15.68 \pm 0.89$ & $20.03 \pm 1.52$ & $6.73 \pm 1.32$ \\
\hline Diacetyl $(\mathrm{mg} / \mathrm{L})$ & $1.21 \pm 0.18$ & $0.89 \pm 0.07$ & $1.33 \pm 0.87$ & $0.51 \pm 0.27$ \\
\hline Titratable acidity ${ }^{3}\left({ }^{\circ} \mathrm{T}\right)$ & $73.36 \pm 2.25$ & $65.22 \pm 1.76$ & $92.43 \pm 10.23$ & $82.36 \pm 3.23$ \\
\hline Viscosity $(\mathrm{Pa} \cdot \mathrm{s})$ & $4.37 \pm 0.31$ & $6.68 \pm 0.52$ & $5.45 \pm 2.42$ & $3.06 \pm 1.56$ \\
\hline Sensory score ${ }^{4}$ & $7.93 \pm 0.26$ & $8.02 \pm 0.19$ & $\mathrm{ND}^{5}$ & $8.05 \pm 0.37$ \\
\hline
\end{tabular}

${ }^{1}$ Data were the average value of 12 samples and determined after collection.

${ }^{2}$ Four plain set-style yogurt samples were collected from the market and fermented with Streptococcus thermophilus and Lactobacillus bulgaricus. Data were the average value of 4 samples.

${ }^{3}$ Expressed as Thorner degrees $\left({ }^{\circ} \mathrm{T}\right)$.

${ }^{4}$ Scale: 1 = poor quality to $10=$ excellent quality.

${ }^{5}$ Not determined.

system, but only some LAB can withstand the adverse gastrointestinal environment to deliver these benefits (Huppertz et al., 2004). Generally, yogurt that confers these health effects contains more than $10^{6} \mathrm{cfu} / \mathrm{g}$ of viable LAB at the time of consumption (Vanderhoof and Young, 1998). In our study, yogurt contained more than $10^{7} \mathrm{cfu} / \mathrm{g}$ of viable LAB during storage, indicating that it could provide health benefits to consumers.

Microbial contamination causes large losses during the production and storage of dairy products. The increased demand for natural foods without chemical preservatives also makes it important to select LAB with good antimicrobial and fermentation properties (Cleveland et al., 2001). Lactic acid bacteria usually produce some antimicrobial substances, such as lactic acid, $\mathrm{H}_{2} \mathrm{O}_{2}$, and bacteriocins, which inhibit the growth of spoilage organisms (Reid and Burton, 2002). Excluding the influence of acid and $\mathrm{H}_{2} \mathrm{O}_{2}$, strains SCA52 ( $L$. fermentum) and SCA7 (L. plantarum) inhibited some indicators (Table 3), suggesting that they produced a bacteriocin-like substance. Previous studies have isolated various bacteriocins from LAB, such as nisin from Lactococcus lactis ssp. lactis and plantarin from L. plantarum (Settanni and Corsetti, 2008), but bacteriocin production by $L$. fermentum has rarely been reported. The chemical structure and characteristics of the bacteriocin-like substance produced by SCA52 require further study.

Analyses were conducted based on flavor components, viscosity, and sensory quality to clarify the contribution of SCA52 and SCA16 to the properties of Xueo that distinguish it from other marketed yogurts (Table 5). Flavor components of fermented milk are the end products of bacterial metabolism. The main flavor compounds presented in fermented milk are acetaldehyde, diacetyl, lactate, and acetate (Marshall, 1987; Chammas et al., 2006). In the present study, the concentrations of acetaldehyde, diacetyl, and acetate in yogurt fermented with SCA52 were similar to Xueo and higher than those in marketed yogurts. Although a special Xueo flavor was formed by the mutual actions of microorganisms, SCA52 (L. fermentum) presented the main flavor compounds, and the viscosity of Xueo may have been formed by E. durans (SCA16). Compared with currently marketed yogurts, those fermented with SCA16 and SCA52 had a different flavor, one that received a positive sensory quality score. The special flavor and viscous texture of Xueo may be the main reason why the ethnic people in this region like this product. Thus, mixing selected strains as starters for developing a Xueo-flavored yogurt should be considered.

\section{CONCLUSIONS}

The dominant LAB in Xueo, a traditional fermented milk product, were $E$. durans, $L$. fermentum, and $L$. paracasei. The special flavor and texture of yogurts depended on the mutual action of these LAB. Enterococcus durans probably contributes to the texture of Xueo and Lactobacillus mainly produces acidity and contributes to the product's unique flavor. Using artisanal strains of LAB to produce similar Xueo-flavored yogurt should be considered.

\section{ACKNOWLEDGMENTS}

This study was supported by the "Chun-hui Project" of China (Z2007-1-61002).

\section{REFERENCES}

Airidengcaicike, X. Chen, X. Du, W. Wang, J. Zhang, Z. Sun, W. Liu, L. Li, T. Sun, and H. Zhang. 2010. Isolation and identification of cultivable lactic acid bacteria in traditional fermented milk of Tibet in China. Int. J. Dairy Technol. 63:437-444. 
Ao, X. L., N. Lu, X. P. Zhang, and C. Li. 2005. Selection of super LAB strains from natural fermented milk in Sichuan-Tibet plateau. China Dairy Industry 33:23-26.

Benkerroum, N., M. Misbah, W. E. Sandine, and A. T. Elaraki. 1993. Development and use of a selective medium for isolation of Leuconostoc spp. from vegetables and dairy products. Appl. Environ. Microbiol. 59:607-609.

Broadbent, J. R., D. J. McMahon, D. L. Welker, C. J. Oberg, and S. Moineau. 2003. Biochemistry, genetics, and applications of exopolysaccharide production in Streptococcus thermophilus: A review. J. Dairy Sci. 86:407-423.

Chammas, G. I., R. Saliba, G. Corrieu, and C. Béal. 2006. Characterisation of lactic acid bacteria isolated from fermented milk "laban". Int. J. Food Microbiol. 110:52-61.

Cleveland, J., T. J. Montville, I. F. Nes, and M. L. Chikindas. 2001. Bacteriocins: Safe, natural antimicrobials for food preservation. Int. J. Food Microbiol. 71:1-20.

De Man, J. C., M. Rogosa, and M. E. Sharpe. 1960. A medium for the cultivation of lactobacilli. J. Appl. Microbiol. 23:130-135.

Devriese, L. A., B. Poutrel, R. Kilpper-Bälz, and K. H. Schleifer. 1983. Staphylococcus gallinarum and Staphylococcus caprae, two new species from animals. Int. J. Syst. Bacteriol. 33:480-486.

Devriese, L. A., M. Vancanneyt, P. Descheemaeker, M. Baele, H. W. Van Landuyt, B. Gordts, P. Butaye, J. Swings, and F. Haesebrouck. 2002. Differentiation and identification of Enterococcus durans, E. hirae and E. villorum. J. Appl. Microbiol. 92:821-827.

De Vuyst, L., M. Zamfir, F. Mozzi, T. Adriany, V. Marshall, B. Degeest, and F. Vaningelgem. 2003. Exopolysaccharide-producing Streptococcus thermophilus strains as functional starter cultures in the production of fermented milks. Int. Dairy J. 13:707-717.

Dewan, S., and J. P. Tamang. 2006. Microbial and analytical characterization of chhu, a traditional fermented milk product of the Sikkim Himalayas. J. Sci. Ind. Res. (India) 65:747-752.

Dewan, S., and J. P. Tamang. 2007. Dominant lactic acid bacteria and their technological properties isolated from the Himalayan ethnic fermented milk products. Antonie Van Leeuwenhoek 92:343-352.

Elliker, P. R., A. W. Anderson, and G. Hannesson. 1956. An agar culture medium for lactic acid streptococci and lactobacilli. J. Dairy Sci. 39:1611-1612.

Foulquié Moreno, M. R., P. Sarantinopoulos, E. Tsakalidou, and L. De Vuyst. 2006. The role and application of enterococci in food and health. Int. J. Food Microbiol. 106:1-24.

Hashim, I. B., A. H. Khalil, and H. Habib. 2009. Quality and acceptability of a set-type yogurt made from camel milk. J. Dairy Sci 92:857-862.

Huppertz, T., P. F. Fox, and A. L. Kelly. 2004. Influence of high pressure treatment on the acidification of bovine milk by lactic acid bacteria. Milchwissenschaft 59:246-249.

ISO. 1993. Sensory analysis - General guidance for the selection, training and monitoring of assessors-Part 1: Selected assessors. ISO 8586-1. International Organization for Standardization, Geneva, Switzerland.

ISO. 2008. Sensory analysis-General guidance for the selection, training and monitoring of assessors-Part 2: Experts sensory assessors. ISO 8586-2. International Organization for Standardization, Geneva, Switzerland.

Jokovic, N., M. Nikolic, J. Begovic, B. Jovcic, D. Savic, and L. Topisirovic. 2008. A survey of the lactic acid bacteria isolated from Serbian artisanal dairy product kajmak. Int. J. Food Microbiol. 127:305-311

Leroy, F., and L. De Vuyst. 2004. Lactic acid bacteria as functional starter cultures for the food fermentation industry. Trends Food Sci. Technol. 15:67-78.
Marshall, V. M. 1987. Lactic acid bacteria: Starters for flavour. FEMS Microbiol. Rev. 46:327-336.

Naser, S., F. L. Thompson, B. Hoste, D. Gevers, K. Vandemeulebroecke, I. Cleenwerck, C. C. Thompson, M. Vancanneyt, and J. Swings. 2005. Phylogeny and identification of enterococci by atp $A$ gene sequence analysis. J. Clin. Microbiol. 43:2224-2230.

Nazef, L., Y. Belguesmia, A. Tani, H. Prévost, and D. Drider. 2008 Identification of lactic acid bacteria from poultry feces: Evidence on anti-Campylobacter and anti-Listeria activities. Poult. Sci. $87: 329-334$

Patrignani, F., R. Lanciotti, J. M. Mathara, M. E. Guerzoni, and W. H. Holzapfel. 2006. Potential of functional strains, isolated from traditional Maasai milk, as starters for the production of fermented milks. Int. J. Food Microbiol. 107:1-11.

Purwandari, U., N. P. Shah, and T. Vasiljevic. 2007. Effects of exopolysaccharide-producing strains of Streptococcus thermophilus on technological and rheological properties of set-type yoghurt. Int. Dairy J. 17:1344-1352.

Reid, G., and J. Burton. 2002. Use of Lactobacillus to prevent infection by pathogenic bacteria. Microbes Infect. 4:319-324.

Settanni, L., and A. Corsetti. 2008. Application of bacteriocins in vegetable food biopreservation. Int. J. Food Microbiol. 121:123-138.

St-Gelais, D., J. Lessard, C. P. Champagne, and J. C. Vuillemard 2009. Production of fresh Cheddar cheese curds with controlled postacidification and enhanced flavor. J. Dairy Sci. 92:1856-1863.

Tamura, K., J. Dudley, M. Nei, and S. Kumar. 2007. MEGA4: Molecular evolutionary genetics analysis (MEGA) software version 4.0 Mol. Biol. Evol. 24:1596-1599.

Terzic-Vidojevic, A., M. Vukasinovic, K. Veljovic, M. Ostojic, and L. Topisirovic. 2007. Characterization of microflora in homemade semi-hard white Zlatar cheese. Int. J. Food Microbiol. 114:36-42.

Thompson, J. D., D. G. Higgins, and T. J. Gibson. 1994. CLUSTAL $\mathrm{W}$ : Improving the sensitivity of progressive multiple sequence alignment through sequence weighting, position-specific gap penalties and weight matrix choice. Nucleic Acids Res. 22:4673-4680.

Torriani, S., G. E. Felis, and F. Dellaglio. 2001. Differentiation of $L a c$ tobacillus plantarum, L. pentosus, and L. paraplantarum by recA gene sequence analysis and multiplex PCR assay with recA genederived primers. 2001. Appl. Environ. Microbiol. 67:3450-3454.

Vanderhoof, J. A., and R. J. Young. 1998. Use of probiotics in childhood gastrointestinal disorders. J. Pediatr. Gastroenterol. Nutr. $27: 323-332$.

Vinderola, C. G., P. Mocchiutti, and J. A. Reinheimer. 2002. Interactions among lactic acid starter and probiotic bacteria used for fermented dairy products. J. Dairy Sci. 85:721-729.

Wilmotte, A., Y. Van de Peer, A. Goris, S. Chapelle, R. De Baere, B. Nelissen, J.-M. Neefs, G. L. Hennebert, and R. De Wachter. 1993. Evolutionary relationships among higher fungi inferred from small ribosomal subunit RNA sequence analysis. Syst. Appl. Microbiol. 16:436-444.

Yang, J., Y. Cao, Y. Cai, and F. Terada. 2010. Natural populations of lactic acid bacteria isolated from vegetable residues and silage fermentation. J. Dairy Sci. 93:3136-3145.

Zamfir, M., M. Vancanneyt, L. Makras, F. Vaningelgem, K. Lefebvre, B. Pot, J. Swings, and L. De Vuyst. 2006. Biodiversity of lactic acid bacteria in Romanian dairy products. Syst. Appl. Microbiol. $29: 487-495$

Zhang, H., J. Xu, J. Wang, Menghebilige, T. Sun, H. Li, and M. Guo. 2008. A survey on chemical and microbiological composition of kurut, naturally fermented yak milk from Qinghai in China. Food Contr. 19:578-586. 